\title{
LA-UR-14-28018
}

Approved for public release; distribution is unlimited.

Title: $\quad$ Mechanical Requirements and Testing Procedure for the Target and Window

Author(s): $\quad$ Woloshun, Keith Albert

Intended for: Report

Issued: 
Disclaimer:

Los Alamos National Laboratory, an affirmative action/equal opportunity employer,is operated by the Los Alamos National Security, LLC for the National NuclearSecurity Administration of the U.S. Department of Energy under contract DE-AC52-06NA25396. By approving this article, the publisher recognizes that the U.S. Government retains nonexclusive, royalty-free license to publish or reproduce the published form of this contribution, or to allow others to do so, for U.S. Government purposes. Los Alamos National Laboratory requests that the publisher identify this article as work performed under the auspices of the U.S. Departmentof Energy. Los Alamos National Laboratory strongly supports academic freedom and a researcher's right to publish; as an institution, however, the Laboratory does not endorse the viewpoint of a publication or guarantee its technical correctness. 


\title{
Mechanical Requirements and Testing Procedure for the Target and Window
}

\author{
NorthStar FY14 Activity 2, Deliverable 1 (A1616D1)
}

\section{Keith Woloshun}

\section{September 26, 2014}

\section{Window}

The window, along with the housing, constitutes a part subjected to primary (pressure) and secondary (thermal) stresses. ASME BPVC provides our guidance for establishing acceptance criteria. This code establishes an allowable stress dependent on Ultimate Tensile Stress (UTS) as S = UTS/3.5, with UTS determined at the temperature of the location of the part under stress. The target housing is under $100^{\circ} \mathrm{C}$ everywhere except the window, so room temperature UTS is appropriate, and since the housing thickness can be increased as necessary without deleterious effects the housing needs only to be checked against the allowable stress and modified as necessary.

The window directly receives beam heating and consequently temperature rise and thermal stress in addition to the pressure loading. Reducing thermal load requires thinning and/or contouring the window, while reducing the primary stress caused by the pressure load is increased by thinning of the window but potentially also reduced by contouring. While the allowable stress $S$ defined above applies to the primary stress, the combined stress (primary plus secondary thermal) needs only be less than $3 * S$. That this criterion is only a small measure below UTS is notable, particularly for ASME code that generally is quite restrictive. For the Mo99 target window, more restrictive criteria will be used to insure that combined stress remains below yield stress.

In summary, the window mechanical requirement is primary stress below UTS/3.5, and combined stress below yield stress. Acceptance test shall be as per ASME BPVC. Code requires a pressure test at 1.3 times the design pressure. For the situation where the allowable stress is lower based on operating temperature, the pressure test can be conducted at room temperature provided that the test pressure is increased by the factor $\mathrm{S}_{\mathrm{RT}} / \mathrm{S}_{\mathrm{OT}}$, where subscripts $\mathrm{RT}$ and $\mathrm{OT}$ are room and operating temperature, respectively.

Up to now, annealed Alloy 718 has been used for the window. Precipitation hardened material is considerably stronger. The annealed material has been used because it is readily available but also because of some concern for change in material properties with use at elevated temperature; specifically partial or complete annealing and loss of the advantage of the hardening process. This will be looked more closely as the design evolves. In Figure 1 presents 4 curves showing yield stress ( $\sigma_{\mathrm{YP}}$ ) and UTS for the annealed and hardened material. Note that there are 2 curves for each instance, and there is considerable range. The Certification of Test for the material we are using has UTS greater than the mean curve in Figure 1 for the hardened material, and virtually equal to the INCO yield strength curve for the annealed material. Therefore, these are acceptable curves for establishing allowable stress for both the annealed and hardened material. 


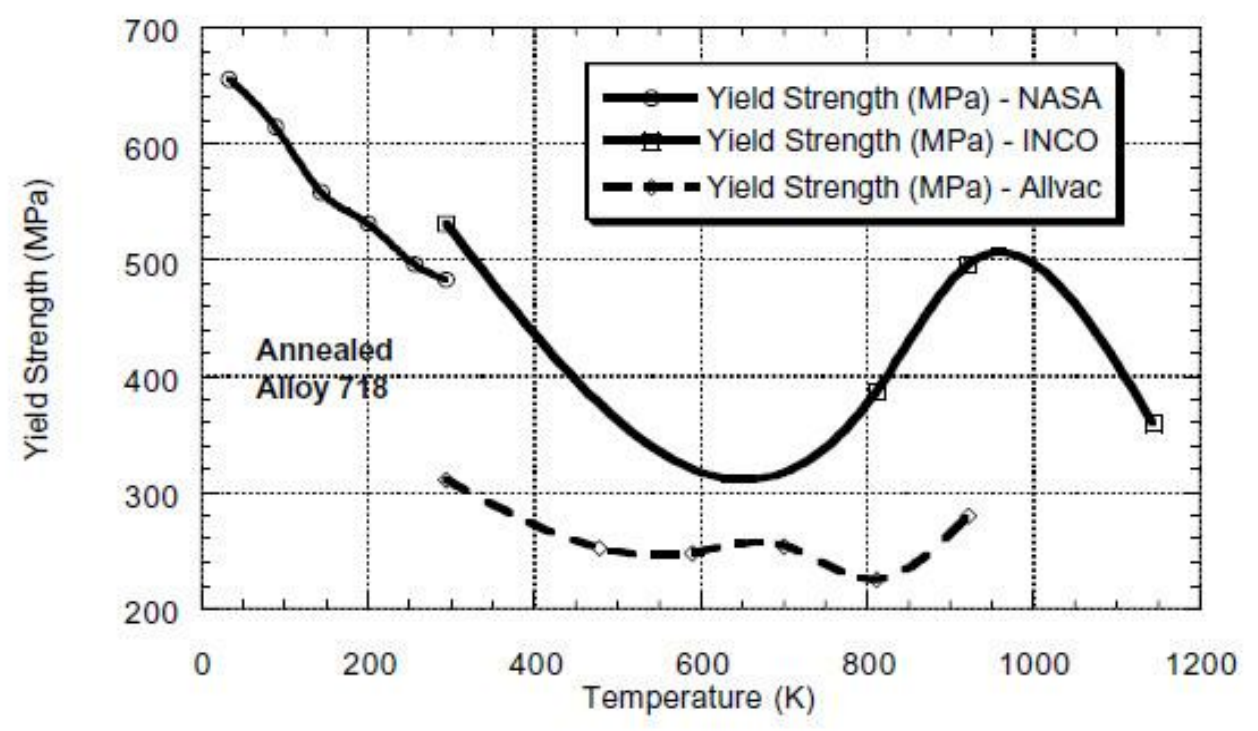

Figure 2-16. Effect of test temperature on the yield strength of three annealed Alloy 718 materials.

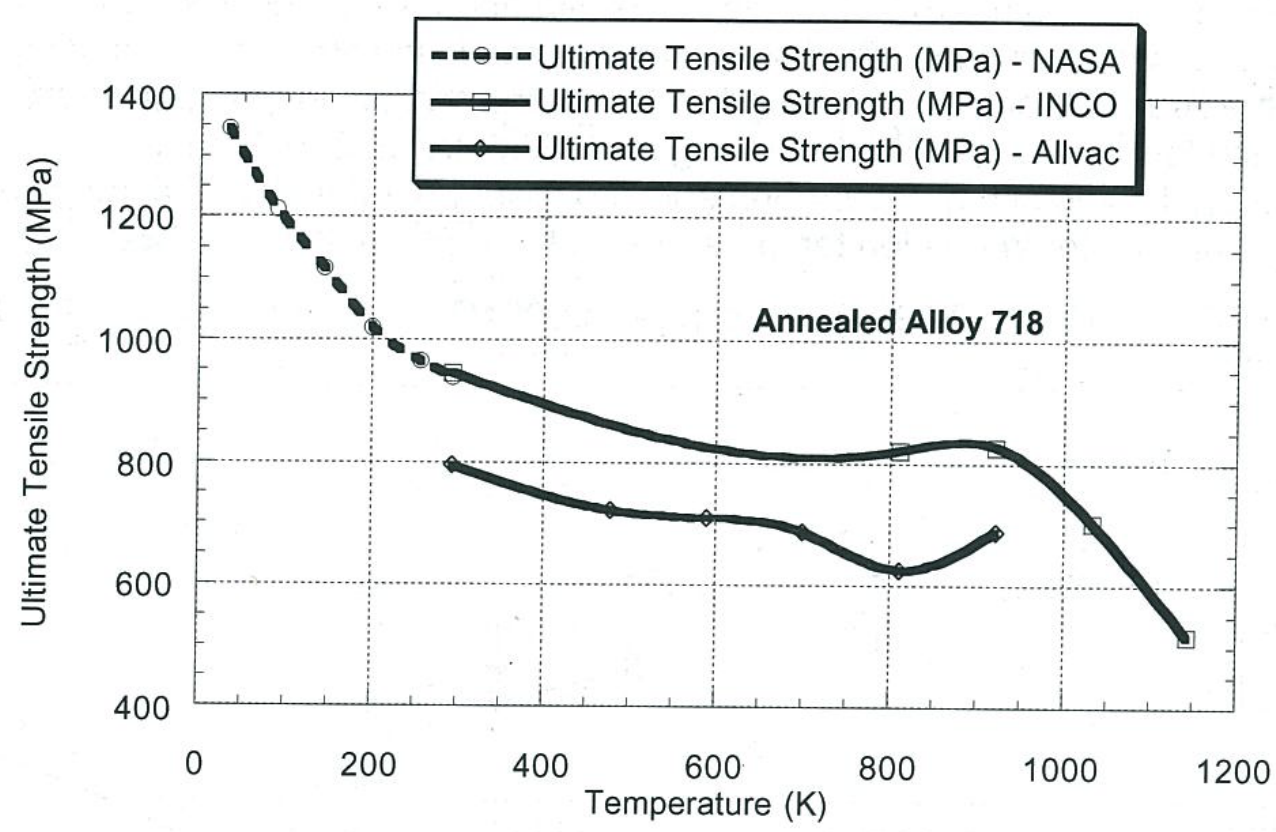

Figure 2-22. Effect of test temperature on the ultimate tensile strength of three annealed Alloy 718 heats. 


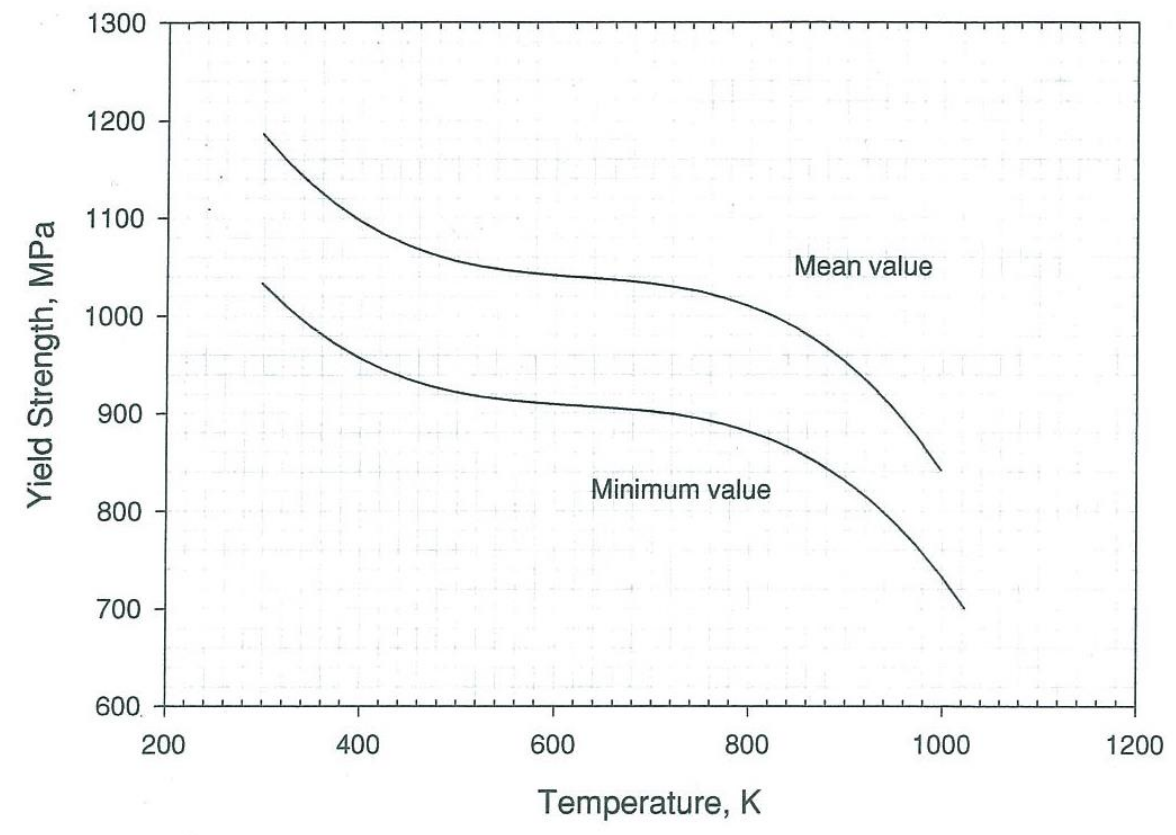

Figure 2-14. Yield strength of precipitation-hardened Alloy 718 as a function of temperature. The upper curve is the average value of yield strength, and the lower curve is the minimum expected value.

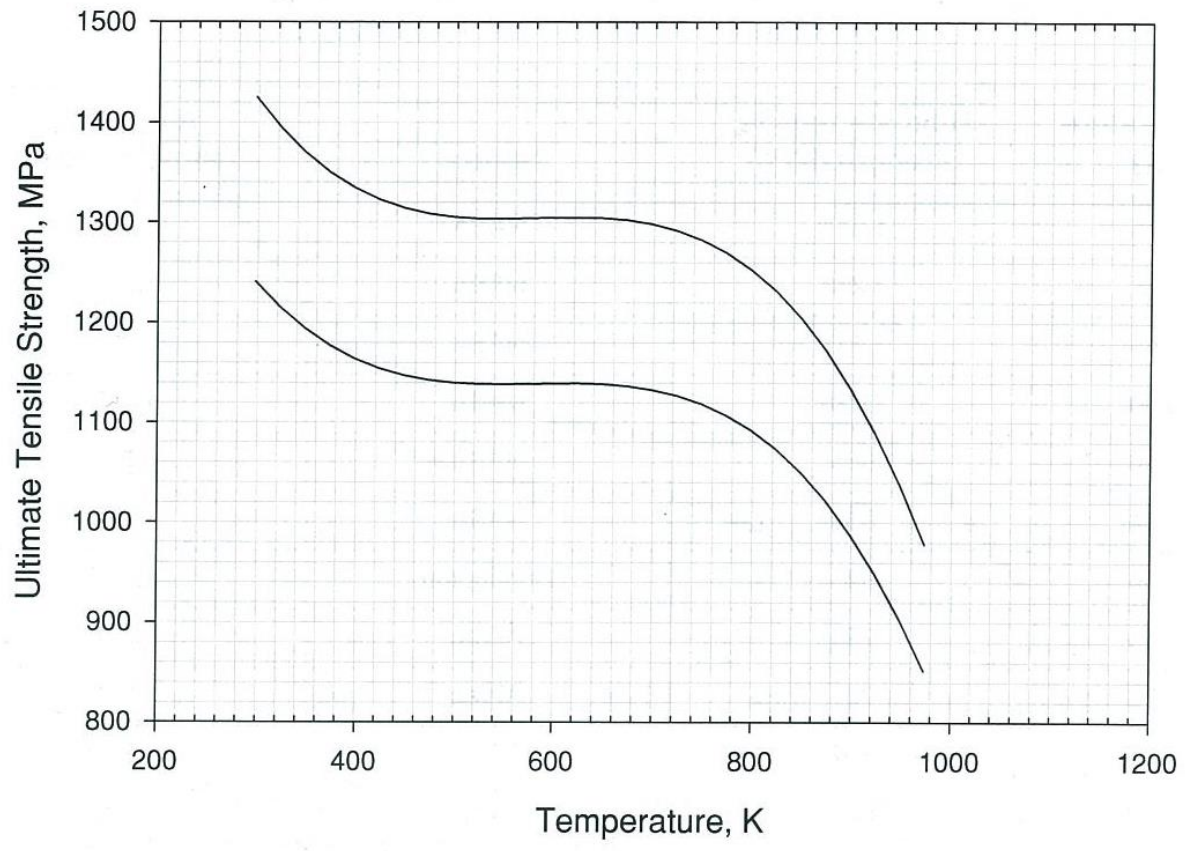

Figure 2-21. Ultimate tensile strength of precipitation-hardened Alloy 718 as a function of temperature. The upper curve is the average value of ultimate tensile strength and the lower curve is the minimum expected value.

Figure 1. $\sigma_{Y P}$ and UTS as a function of temperature for annealed and precipitation hardened Alloy 718. Figure numbers refer to the source document, "AFCI Materials Handbook," Rev. 4, Oct 2003. 
The design continues to evolve, with window temperatures as high as $1000 \mathrm{~K}$. The current design has a peak window temperature of $700 \mathrm{~K}$. There is a notable reduction of strength in the material at and above $1000 \mathrm{~K}$, particularly for the hardened material. Allowable stress at 700 and $1000 \mathrm{~K}$ is 228 and 214 MPa for annealed material, and 371 and $280 \mathrm{MPa}$ for precipitation hardened. The бyp criterion for combined stress maximum is $320 \mathrm{MPa}$ for annealed material, corresponding to the minimum in the curve at approximately $700 \mathrm{~K}$. For precipitation hardened at 700 and $1000 \mathrm{~K}$ the $\sigma_{\mathrm{YP}}$ limit is 1050 and $875 \mathrm{MPa}$, respectively.

Other window materials have been evaluated. The primary criterion is high UTS up to $1000^{\circ} \mathrm{C}$. In Figure 2 is shown the UTS as a function of temperature for a variety of materials. Although the strength of Inconel 718 has dropped considerably by $1000^{\circ} \mathrm{C}$, the higher strength options are all refractory metals, which introduces problems of joining, ductile-brittle transition temperature, and potentially cost and machining issues. Of these, TZM is the most likely candidate.

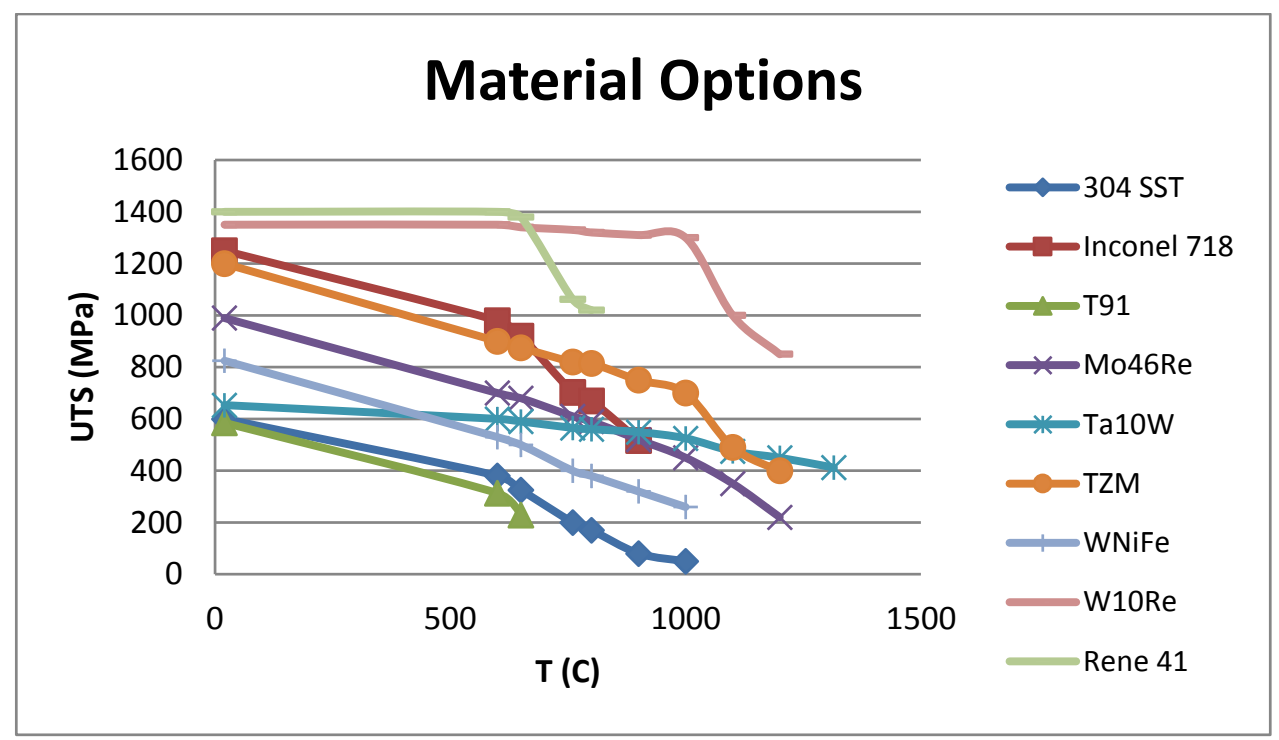

Figure 2. Plot of UTS vs temperature for selected steels and refractory metals.

\section{Target}

The target disks are held in a circular slot in a stainless steel holder. The holder is sized and toleranced so that the disks fit without constraint in the holder at the temperature of the parts under the irradiation condition. The hottest disks reach a temperature of $1263 \mathrm{~K}$ at the center. Figure 3 shows the temperature contour plot of the hottest disk, Disk 14. Temperature increase causes thermal expansion through the thickness and radially. The radial thermal expansion in particular causes thermal stresses, aggravated by the fact that the center heats significantly more than the edge. Thus the center of the disk wishes to expand radially but the relatively cool outer edge constrains that motion.

The resulting thermal stress is shown in Figure 4, showing a peak thermal stress of $281 \mathrm{MPa}$ at the center. Stress/strain curves for molybdenum are shown in the plot in Figure 5 . From the curve at $982^{\circ} \mathrm{C}$, it is evident that plastic deformation will result, with a maximum deformation of $0.002 \mathrm{in}(0.05 \mathrm{~mm})$. 
Actual deformation is shown in Figures 6 and 7 in one radial plane and in the " $Z$ " direction through the thickness.

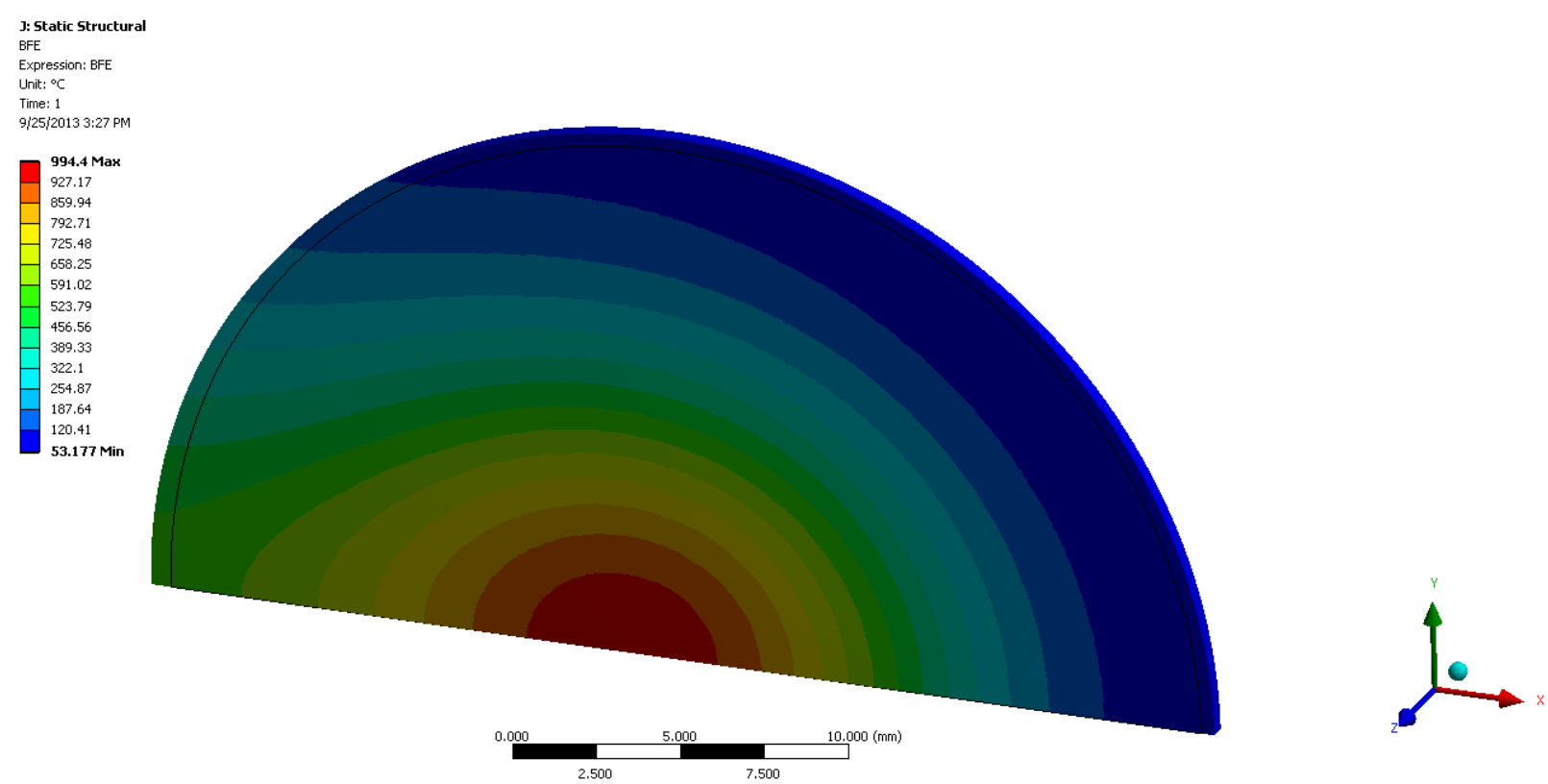

Figure 3. Disk 14 temperature profile under the current plant design irradiation and helium cooling conditions.

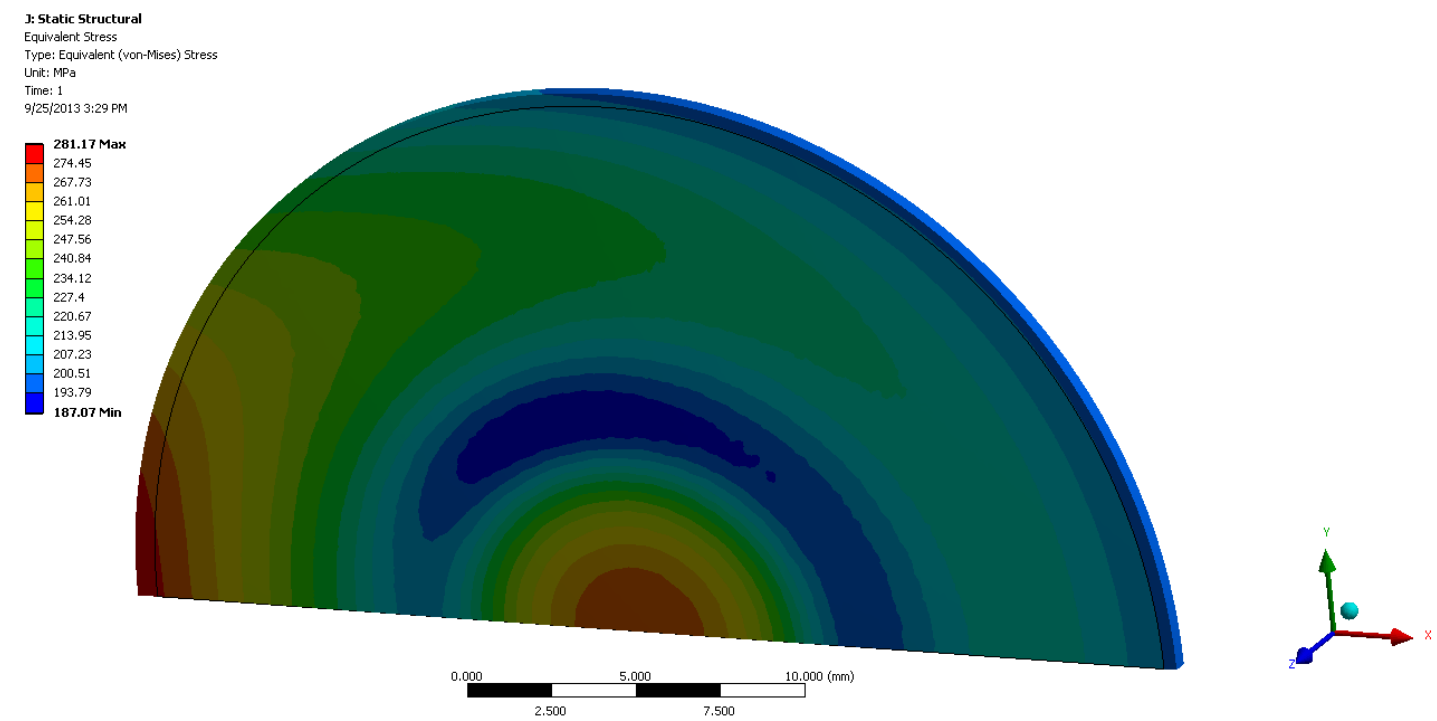

Figure 4. Stress profile of Disk 14 


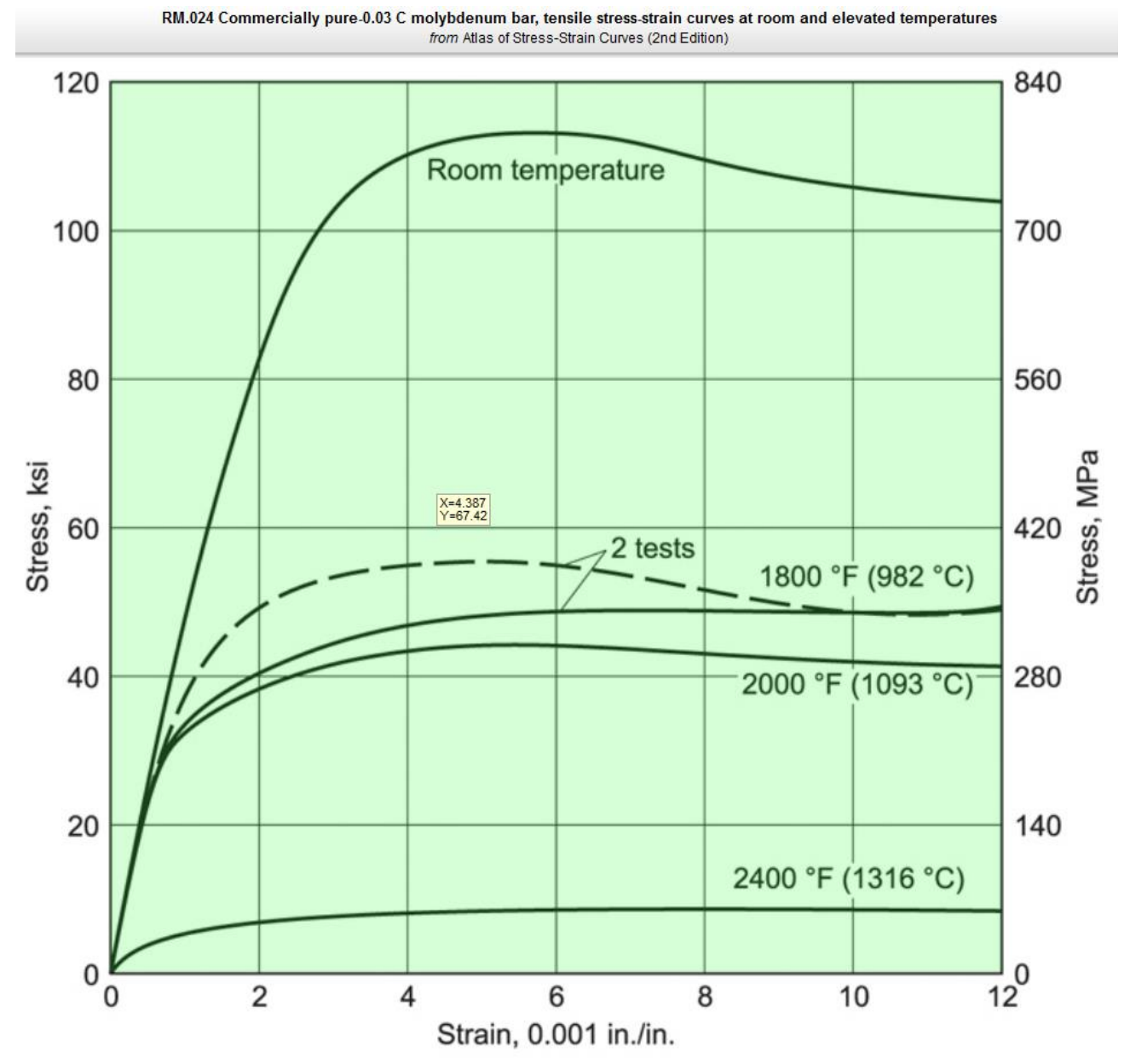

$16 \mathrm{~mm}\left(5 / 8 \mathrm{in}\right.$.) thick bar stress relieved at $982{ }^{\circ} \mathrm{C}$ $\left(1800{ }^{\circ} \mathrm{F}\right)$ for $1 \mathrm{~h}$. Tested at a strain rate of $0.005 / \mathrm{min}$

Figure 5. Molybdenum stress/strain curves. 

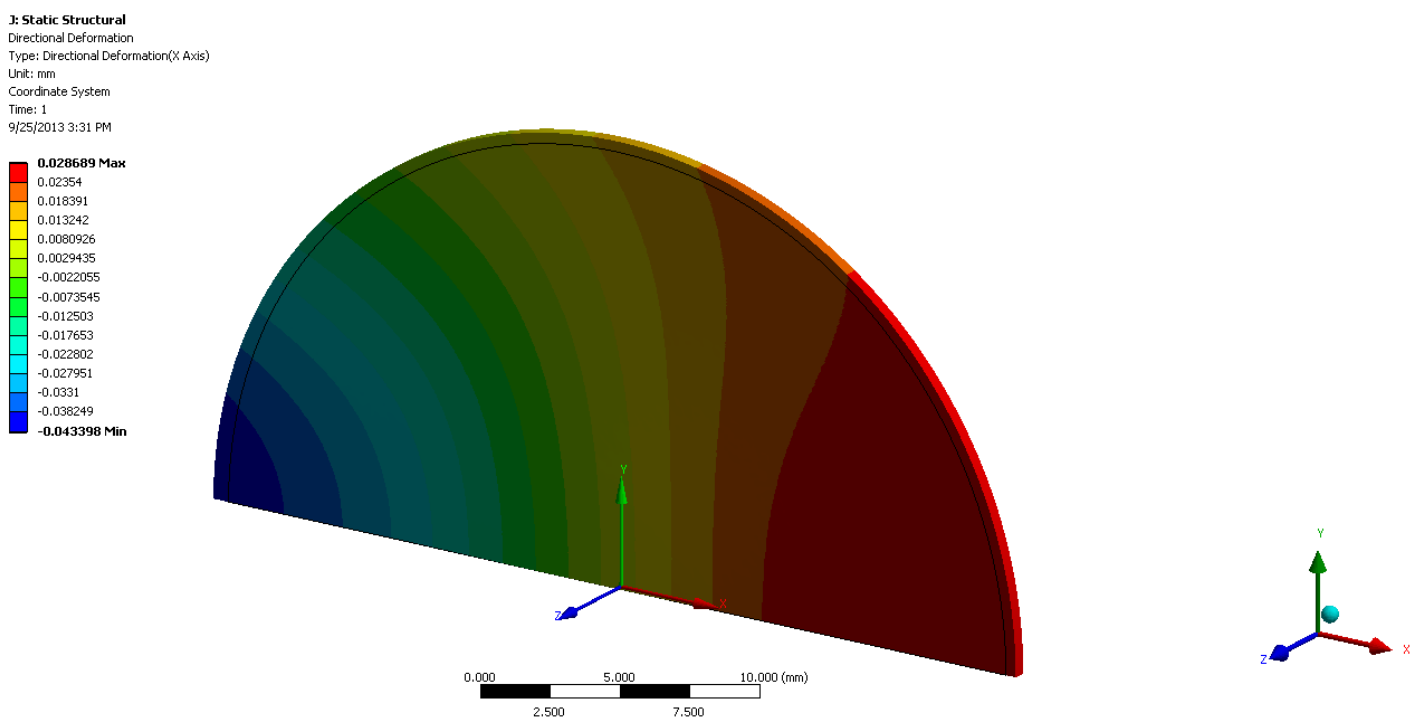

Figure 6. Disk deformation in the radial direction
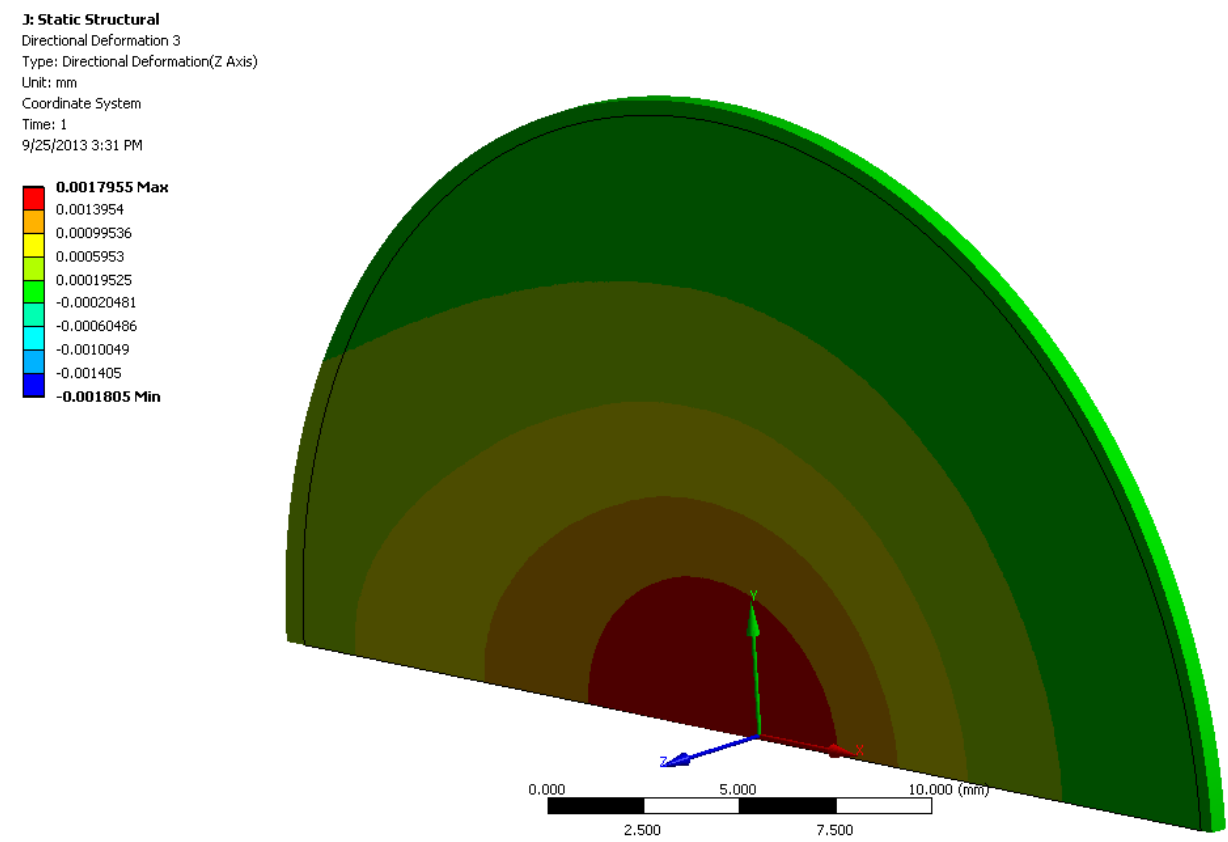

Figure 7. Disk deformation in the direction through the thickness.

The objective is to establish a test of the individual disks to insure that these thermal stresses will not fracture the disk, which could quite likely alter the coolant flow field in a negative way. Without beam heating, the volumetric heating profile in the disk is virtually impossible to replicate. In the interest of a readily and easily applicable test, a mechanical load test is proposed. While recognizing the distinction between primary and secondary stresses and the effect of temperature on the strength and ductility of a metal, a test using a central mechanical load on the disk with simply supported edge, conducted at 
room temperature, while recreating the peak stress in the center of the disk under thermal load is proposed. On the $29 \mathrm{~mm}$ diameter disks currently baseline for the plant target, a $2 \mathrm{~mm}$ diameter punch with a $17.8 \mathrm{~kg}$ load on the center of the disk replicates the $281 \mathrm{MPa}$ stress (Figure 8).

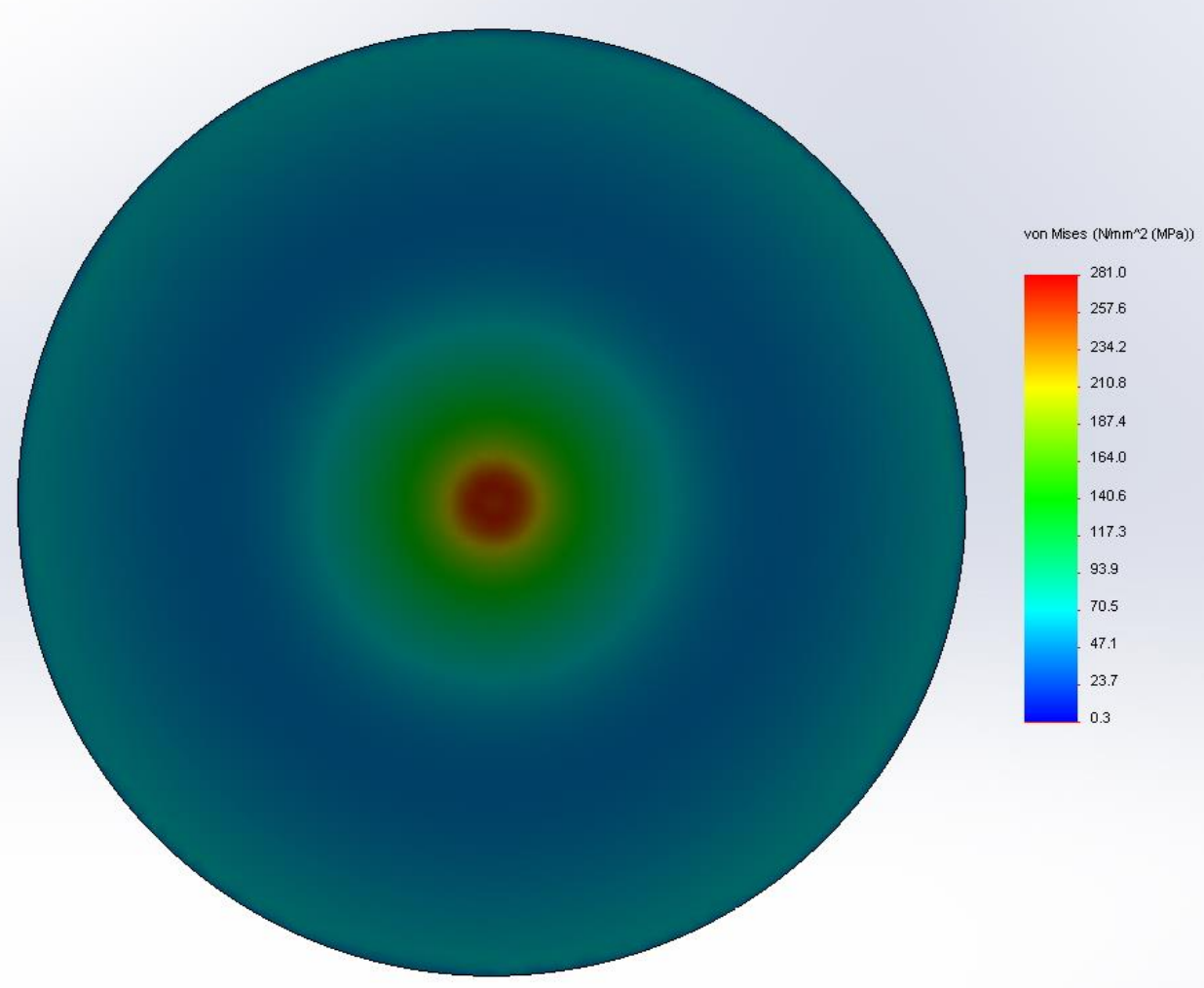

Figure 8. Disk stress profile plot with $17.8 \mathrm{~kg}$ load applied to the center, sith simply supported edge at the circumference.

The punch test apparatus is shown in Figure 9. Typical results are shown in Figure 10. Brittle failure at less than the desired $280 \mathrm{MPa}$, but based on the observed deflection, a mechanical test based on deflection of 100 to 200 microns may be valid. Meanwhile, a test method using an e-beam welder to precisely heat the disk center and create the desired temperature profile is being explored. A thermal test requires heating to temperatures greater than can be endured by Mo in air without rapid oxidation; this test must be performed in vacuum. 

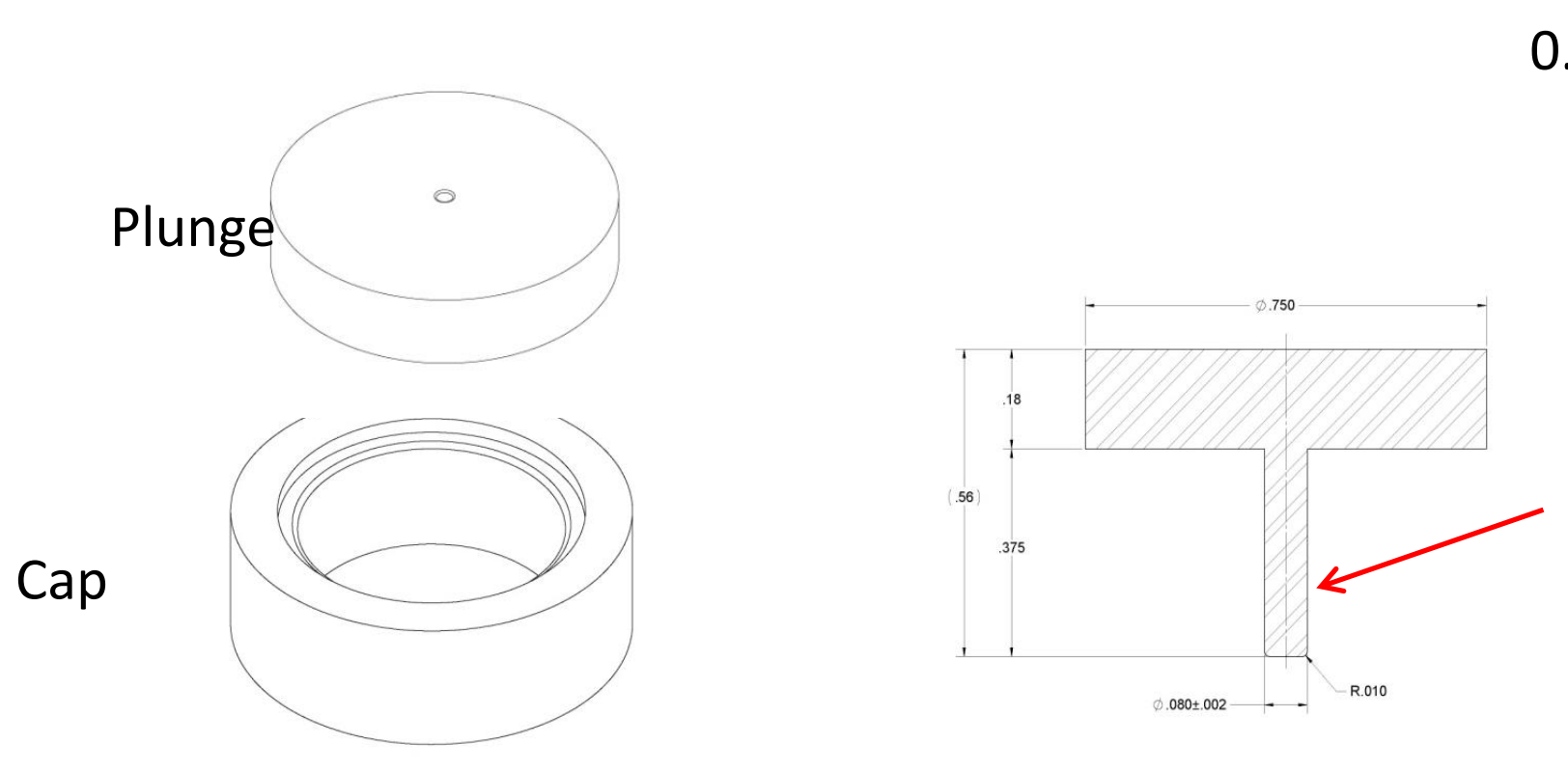

Figure 9. Target disk punch test apparatus. The disk is fitted into the base and the cap placed over the disk. The cap provides a guide hole to center and align the punch.

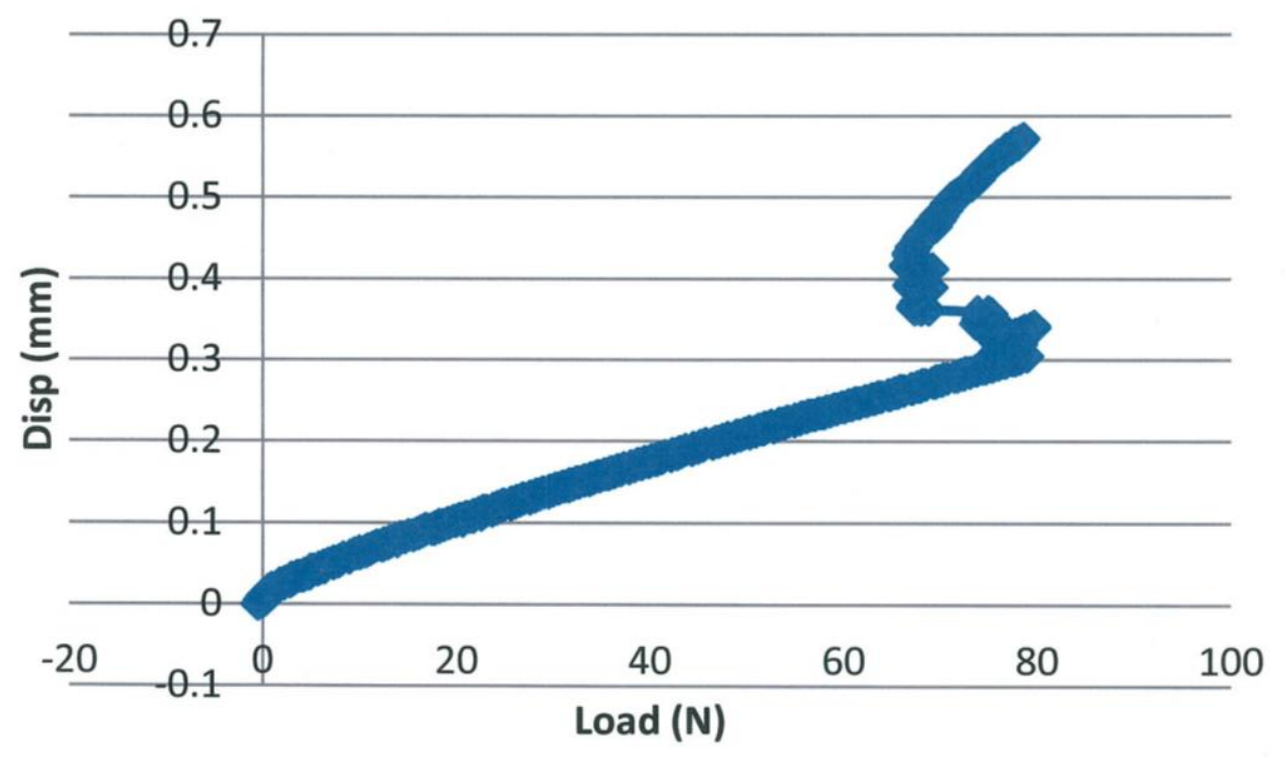

Figure 10. Load test results on a sample disk.

\section{Conclusion}


The window will be designed and tested in accordance with ASME BPVC standards and requirements. Code requires a pressure test of $130 \%$ of the design load, currently 400 psig. The target disks will be qualified using either a mechanical test similar to that shown above, or to a thermal test using a welder. Ideally, a thermal test would be used to validate a mechanical test that can be performed rapidly at room temperature for ease of use on site and for a large number of disks. 